\title{
Metastatic Lip and Oral Cavity Carcinoma
}

National Cancer Institute

\section{Source}

National Cancer Institute. Metastatic Lip and Oral Cavity Carcinoma. NCI Thesaurus.

Code C156086.

A carcinoma that arises from the lip and/or oral cavity and has metastasized to another anatomic site. 